\title{
Radial artery patency and clinical outcomes: Five-year interim results of a randomized trial
}

\author{
Brian F. Buxton, MB, BS, FRACS, FRCS, FACS, FRCS $(C)^{a}$ \\ Jai S. Raman, MBBS, MMed, FRACS ${ }^{a}$ \\ Permyos Ruengsakulrach, MD, PhD, FRCST ${ }^{\mathrm{a}}$ \\ Ian Gordon, MSc, PhD, AStat ${ }^{b}$ \\ Alex Rosalion, BSc, MB, BS, FRACS ${ }^{a}$ \\ Rinaldo Bellomo, MBBS, MD, FRACP ${ }^{d}$ \\ Mark Horrigan, MB, BS, FRACPC \\ David L. Hare, MB, BS, DPM, FRACPC
}
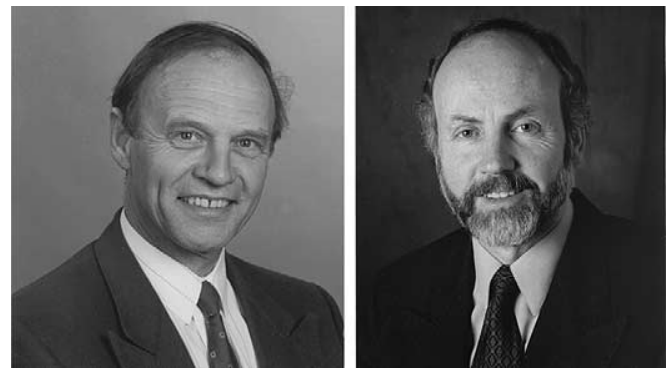

Dr Buxton and Dr Hare
Objective: This study was undertaken to compare elective angiographic patency and cardiac event-free survival of the radial artery graft with that of the free right internal thoracic artery or saphenous vein during a 10-year period after primary coronary artery bypass surgery.

Methods: This prospective, randomized, single-center trial was conducted on two groups of patients undergoing primary coronary artery bypass surgery. In a younger group (group $1, \mathrm{n}=285,<70$ years), the radial artery was compared with the free right internal thoracic artery. In an older group (group $2, \mathrm{n}=153, \geq 70$ years), the radial artery was compared with the saphenous vein. The trial conduit was grafted to the largest available coronary artery other than the left anterior descending coronary artery. Angiography was scheduled at intervals between 0 and 10 years according to a second random assignment. Patients were followed up at yearly intervals to assess clinical outcomes. Clinical outcomes were analyzed on an intent-to-treat basis during the 10-year follow-up with time-related analyses. This interim study reports angiographic and clinical outcome results during the first 5 years.

Results: Graft patency estimates were as follows: 0.95 (95\% confidence interval $0.85-0.99)$ in 39 radial arteries versus 1.0 in 29 right internal thoracic arteries $(P=$ .4 ) in group 1, and 0.86 (95\% confidence interval 0.67-0.99) in 24 radial arteries versus 0.95 (95\% confidence interval $0.83-0.99)$ in 22 saphenous veins $(P=.5)$ in group 2. Cardiac event-free survival estimates were as follows: 0.91 (95\% confidence interval $0.76-0.99)$ for the radial artery versus 0.82 (95\% confidence interval $0.63-0.99)$ for the right internal thoracic artery $(P=.7)$ in group 1 , and $0.84(95 \%$ confidence interval 0.64-0.99) for the radial artery versus 0.89 (95\% confidence interval 0.72-0.99) for the saphenous vein $(P=.9)$ in group 2.

Conclusion: The 5-year interim results do not support the hypothesis that the radial artery has superior patency to or is associated with fewer clinical events than free right internal thoracic artery or saphenous vein grafts.

Address for correspondence: Brian F. Buxton, MD, Director of Cardiac Surgery, HS-5, Austin Hospital, Heidelberg, Victoria 3084, Australia. (E-mail: brian.buxton@ austin.org.au)

J Thorac Cardiovasc Surg 2003;125: $1363-71$

Copyright $\odot 2003$ by The American Association for Thoracic Surgery

$0022-5223 / 2003 \$ 30.00+0$

doi:10.1016/S0022-5223(02)73241-8

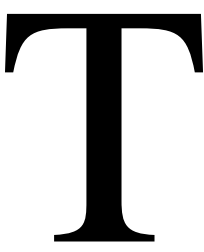

he fates of patients after coronary artery bypass surgery for obstructive coronary artery disease are in part related to the type of bypass conduit. Techniques of bypass surgery have changed through the years, with strong evidence to support the use of one or both in situ internal thoracic arteries (ITAs). Bilateral, compared with single, ITA grafting is associated with increased survival and also fewer ischemic cardiac events. ${ }^{1-3}$ The right and left ITAs grafted to the left anterior 
descending coronary artery (LAD) have identical patency rates, which exceed the rate of the saphenous vein (SV). The patency results of free ITA grafts are inferior to those of in situ grafts, with a 2-fold increase in early graft failure. $^{4}$

Studies indicate that the SV has excellent early patency results; however, between 5 and 10 years there is accelerated graft atheroma and increasing rates of graft failure, so that at 10 years approximately $40 \%$ of grafts have failed. This has led to a search for arteries that could be used to replace the SV. These arteries include the right gastroepiploic artery, inferior epigastric artery, and radial artery (RA). All have demonstrated excellent patency rates in symptom-directed studies; however, there are few data about their durability when studied by elective angiography.

The RA was first used in the early 1970s by Carpentier and colleagues. ${ }^{5}$ It has many desirable characteristics. It is readily available in a length suitable for bypassing most coronary lesions. It is similar in diameter to the proximal coronary arteries, marginally larger than the ITA and smaller than most SV grafts. The use of the RA was revisited by Acar and colleagues ${ }^{6}$ and others, ${ }^{7,8}$ who discovered the excellent late patency in a number of Carpentier and colleagues' early series. These patients had been receiving calcium channel blockers.

RA grafts are receiving increasing acceptance, and their removal is associated with few hand complications, such as ischemia and donor site hematoma, ${ }^{9,10}$ with a lower sternal infection rate, ${ }^{11}$ and with excellent early clinical results. ${ }^{12,13}$ Fremes and associates, ${ }^{8}$ Dietl and Benoit, ${ }^{14}$ and Bhan and colleagues ${ }^{15}$ reported low rates of recurrence of angina, myocardial infarction, and death. Recent angiographic studies have shown that the RA achieves excellent short-term patency when used as a coronary artery bypass conduit. ${ }^{14,16-25}$ Although results of RA grafting are encouraging, most angiographic results are from small numbers of patients who are seen again because of evidence of ischemia. There are few long-term patency rates of RA grafts studied electively in symptom-free patients, and little scientific evidence comparing the RA with the right ITA used as a free graft or with the SV. There is one ongoing randomized study originating from Toronto evaluating the fate of the RA. This study, which is comparing patency between the RA and SV in the same patient, is known as the Radial Artery Patency Study (RAPS) ${ }^{26}$ However, there are no previous studies in which patients have been prospectively randomly assigned to receive either the RA or another bypass conduit. In this study, the Radial Artery Patency and Clinical Outcome (RAPCO) Study, patients are randomly assigned to receive either RA or, in two separate stratified groups, right ITA or SV.

\section{Material and Methods \\ Study Design}

This is a prospective, randomized, single-center trial, stratified into a group younger than 70 years (group 1), in which the RA patency was compared with that of the free right ITA, and a group aged 70 years or more (group 2), in which RA patency was compared with that of the SV graft. Programmed angiography was performed at a predetermined interval between 0 and 10 years according to a second random assignment. In addition, a 5-year angiogram was offered to all patients.

\section{Hypotheses}

The following hypotheses were tested:

1. Angiographic patency of the RA graft is superior to that of the free right ITA or SV graft.

2. Patients who receive RA grafts have clinical outcomes superior to those of patients who receive free right ITA or SV grafts.

\section{Specific Aims}

This study was undertaken to compare elective angiographic patency of the RA with those of the free right ITA and SV during 5 to 10 years after surgery and to assess the survival, myocardial infarction, and reintervention rates in patients with RA grafts versus those with right ITA and SV grafts.

\section{Entry Criteria}

Male or female patients younger than 80 years undergoing elective primary isolated coronary artery bypass surgery and requiring more than one bypass conduit were eligible for the study. An ejection fraction greater than $35 \%$ and at least one non-LAD vessel with a proximal stenosis of at least $70 \%$ and a diameter of at least $1.5 \mathrm{~mm}$ were required.

\section{Exclusion Criteria}

General exclusions. Patients were excluded because of body mass index greater than $35 \mathrm{~kg} / \mathrm{m}^{2}$, renal impairment with serum creatinine level greater than $300 \mu \mathrm{mol} / \mathrm{L}$, lung disease with a forced expiratory volume in 1 second less than $1 \mathrm{~L}$, associated major illnesses (eg, malignancy) with the survival expected to be less than 10 years, concomitant cardiac disease (such as valve disease or a left ventricular aneurysm), chronic heart failure, emergency presentation, or myocardial infarction less than 1 week before surgery.

Specific exclusions. Patients were deemed ineligible if either of the proposed randomly assigned grafts was not available. The RA was not harvested if the recovery time on the modified Allen test was longer than 10 seconds in the nondominant hand. ${ }^{27}$ The right ITA was not removed in patients with poor lung function, chest wall trauma, or previous chest wall radiotherapy. The SV was not used if it was varicose, if the ankle/brachial systolic blood pressure index was less than 0.75 , or if peripheral pulses were absent.

\section{Random Assignment}

All patients received an in situ left ITA graft to the LAD. The choice of the second conduit was determined by random assign- 
TABLE 1. Coronary artery grafts by randomization group

\begin{tabular}{lllc}
\hline & First graft (LAD) & Second graft & $\begin{array}{c}\text { Subsequent } \\
\text { grafts }\end{array}$ \\
\hline RA or free right ITA & Left ITA & RA or right ITA & SV \\
RA or SV graft & Left ITA & RA or SV & SV \\
\hline
\end{tabular}

ment. If additional grafts were required, the SV was used. There were two groups, according to age and current practice. Group 1 consisted of patients younger than 70 years. The trial conduit was either right ITA (control graft) or RA (experimental graft). This trial graft was anastomosed to the largest available non-LAD vessel (Table 1).

Group 2 patients ( $\geq 70$ years) were randomly assigned to receive either SV (control graft) or RA (experimental graft) for the second conduit. Patients with diabetes are known to have more severe atherosclerosis than those without diabetes. Stratification between groups 1 and 2 was performed at 60 rather than 70 years to avoid bilateral ITA harvesting in patients with diabetes older than 60 years because of higher mortality and morbidity rates (Table 1). ${ }^{28-30}$

Random numbers were generated from the Minitab statistical package (Minitab, Inc, State College, Pa) and placed in sealed envelopes. The patient's name, the date, and the name of the person performing the random assignment were recorded on each envelope before it was opened. Random assignment was undertaken by the University Statistical Consulting Center and kept at arm's length from the clinical staff involved. Patient information and consent forms were approved by the institution's human research ethics committee.

\section{Surgical Technique}

The RA was removed from the nondominant arm. The RA was dilated in situ with an intraluminal ejection of $4 \mathrm{~mL}$ of a $1-\mathrm{mM}$ solution of papaverine ( $40 \mathrm{mg}$ in $100 \mathrm{~mL}$ ) with a mixture of $50 \%$ blood and Ringer's lactate solution. This was injected retrogradely into the distal end of the RA, which was clipped and left for 5 minutes to dilate under arterial pressure. The artery was removed and stored in a bath of the same solution. The SV and the right ITA were dilated with the same papaverine mixture and stored in an identical manner to the RA. All operations were performed with cardiopulmonary bypass. The technique of RA harvest and coronary artery bypass grafting has been described previously elsewhere. $^{31-34}$ The left ITA and right ITA were mobilized with a wide pedicle. The left ITA was left in situ for anastomosis to the LAD; the right ITA was used as a free graft. The trial graft was sutured to the largest available non-LAD coronary artery and grafted proximally to the aorta as a standard aorta-coronary bypass graft. All anastomoses were performed by staff surgeons. Sequential anastomoses were permitted between the diagonal artery and the LAD and when using nonstudy SV grafts.

\section{Postoperative Management}

All patients were given milrinone in a loading dose of $25 \mu \mathrm{g} / \mathrm{kg}$ in 15 minutes followed by $0.25 \mu \mathrm{g} /(\mathrm{kg} \cdot \mathrm{min})$ to produce a cardiac index of 2.5 to $3 \mathrm{~L} /\left(\mathrm{m}^{2} \cdot \mathrm{min}\right)$. Milrinone was discontinued if the cardiac index exceeded $3 \mathrm{~L} /\left(\mathrm{m}^{2} \cdot \min \right)$, the mean blood pressure

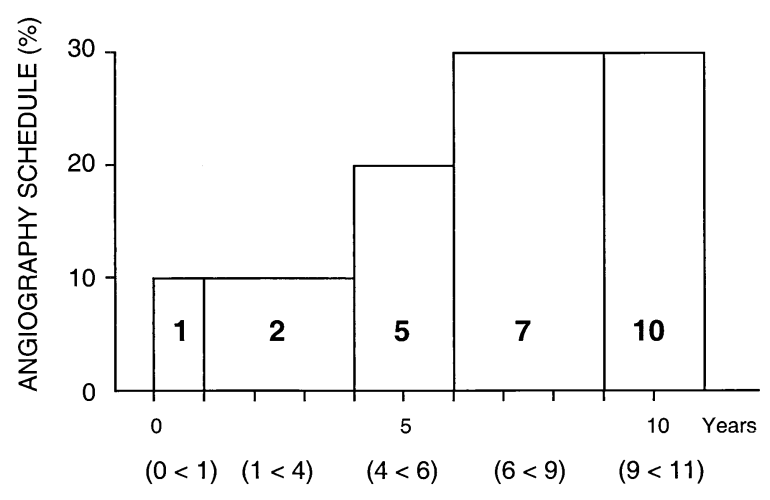

Figure 1. Protocol-directed angiography schedule. Each patient was randomly allocated one of five schedule dates: 1, 2 5, 7, and 10 (range) years. Angiograms were weighted to latter part of 10-year study.

was less than $70 \mathrm{~mm} \mathrm{Hg}$, or the peripheral vascular resistance was less than 1000 dynes $\cdot \mathrm{s} \cdot \mathrm{cm}^{-5}$. Milrinone was continued for the first 12 to 18 hours. After that, oral amlodipine at 2.5 to $5 \mathrm{mg}$ daily was commenced and continued for 6 months. Aspirin at $100 \mathrm{mg}$ per day was commenced the day after surgery and continued indefinitely.

\section{Angiography}

Patients underwent a second random assignment for the timing of the elective coronary angiogram and graft study during the 10 years after surgery. The frequency of protocol-directed angiography was weighted toward the end of the study, because it was anticipated that there would be relatively few events in the first 5 years and thus most of the information would come from the latter part of the study. Ten percent of the patients were randomly assigned to undergo angiography within 12 months from the time of surgery, $10 \%$ at 2 years after the operation, $20 \%$ at 5 years, $30 \%$ at 7 years, and $30 \%$ at 10 years (Figure 1). In addition to the protocol-directed angiography program, all patients were offered an angiogram at 5 years after the operation. Left ventriculography was not performed routinely.

Graft failure was defined as occlusion or at least $70 \%$ stenosis. Graft patency was determined by three independent observers, two surgeons and a cardiologist. Each observer was provided with a copy of the surgeon's operation notes, with identification of the target vessel and the position of the trial coronary graft. True blinding during the assessment was not possible, and furthermore the size and character of the SV and clips on the free arterial grafts made them readily identifiable. The RA, however, was often not distinguishable from the free right ITA. Assessment was made of the graft trunk, and any pathologic findings at the proximal or distal anastomoses were recorded separately. Thrombolysis in Myocardial Infarction (TIMI) ${ }^{35}$ flows and graft stenoses were recorded. Disputed angiographic findings were assessed separately and adjudicated.

\section{Clinical Data Collection}

After discharge from the hospital, those patients recruited into both the control and experimental groups received standard follow-up 
TABLE 2A. Protocol-directed angiographic status, May 2002

\begin{tabular}{|c|c|c|c|c|c|c|c|}
\hline $\begin{array}{l}\text { Protocol-directed } \\
\text { angiographic timing (y) }\end{array}$ & No. & $\begin{array}{c}\text { Refused } \\
\text { angiography }\end{array}$ & $\begin{array}{l}\text { Died before } \\
\text { angiography }\end{array}$ & $\begin{array}{c}\text { Missed } \\
\text { scheduled } \\
\text { date }\end{array}$ & $\begin{array}{l}\text { Not } \\
\text { due }\end{array}$ & $\begin{array}{c}\text { Study } \\
\text { angiograms }\end{array}$ & Total \\
\hline $1(<1)$ & 43 & 6 & 0 & 9 & 0 & 28 & 43 \\
\hline $2.5(1<4)$ & 36 & 3 & 1 & 8 & 12 & 12 & 36 \\
\hline $5(4<6)$ & 74 & 0 & 3 & 0 & 49 & 22 & 74 \\
\hline $7.5(6<9)$ & 118 & 0 & 3 & 0 & 115 & 0 & 118 \\
\hline $10(>9)$ & 125 & 0 & 6 & 0 & 119 & 0 & 125 \\
\hline Total & 396 & 9 & 13 & 17 & 295 & 62 & 396 \\
\hline
\end{tabular}

TABLE 2B. Protocol-directed and optional angiograms, May 2000

\begin{tabular}{lc}
\hline & No. \\
\hline Protocol-directed angiograms only & 53 \\
Optional 5-year angiograms only & 52 \\
Both & $9^{*}$ \\
Total angiograms & 114
\end{tabular}

*Most recent angiogram only used with Kaplan-Meier estimates.

care. All patients were contacted yearly after their coronary artery bypass surgery. At the time of contact, the clinical nurse consultant obtained data regarding patient survival, myocardial infarction, and further revascularization (surgical or percutaneous intervention). Angiography was performed on an outpatient basis to investigate the patency of the RA, right ITA, and SV grafts. Patients underwent yearly clinical review by a cardiac surgeon. Survival was confirmed with the National Death Index, a register of all deaths. ${ }^{36}$ All data are stored in a Visual Fox Pro database (Microsoft Corporation, Redmond, Wash).

\section{Major Outcome Measures}

A major end point of the study was angiographic patency of the RA, right ITA, and SV grafts during a 10-year period after surgery. This interim study assesses the outcomes of 114 angiograms performed during the first 5 years of the study. Other major outcomes were survival and cardiac event-free survival. Death, perioperative or subsequent, was defined as all-cause mortality, and cardiac event-free survival was defined as survival with freedom from myocardial infarction, percutaneous intervention, or reoperation.

\section{Statistical Analysis}

All patients randomly assigned were included in the analyses. Patients whose chosen graft conduit was found during the operation to be unsuitable were included in the clinical analysis on an intent-to-treat basis. The focus of this interim report is 5-year graft patency and cardiac event-free survival. Most angiograms in this study to date were performed in the latter part of the follow-up period. Categoric patency, clinical end points, all-cause mortality, and cardiac event-free survival were analyzed by standard survival analysis techniques. Kaplan-Meier estimates were obtained for each of the two arms of both trials. Because of the random assignment, a simple comparison of the two treatment groups is unbiased. The log-rank statistic was used to test for differences between the survival curves.

Estimation of sample size. The 5-year patency was expected to be high for both trial and control grafts in both groups. In the younger patients (group 1), in whom the RA is being compared with the right ITA, 154 patients in each group are sufficient to detect a true difference of patency percentages of at least $10 \%$ when the patency is $85 \%$ in one group and $95 \%$ in the other, by a 2-sided test with a power of $80 \%$ and the best approximation for comparing two proportions. ${ }^{37}$ In the older patients (group 2), in whom the comparison is between the RA and SV, to detect a difference of at least $15 \%$ for a 2 -sided test with a power of $80 \%$, 84 patients are required in each arm to detect a difference between a patency of $80 \%$ for one treatment and a patency of $95 \%$ for the other.

Enrollment. Between June 1996 and February 2002, a total of 1004 patients were assessed but were not randomly assigned because they failed to meet the entry criteria, for example, the lack of availability of one of the potential trial grafts or presence of one of the major clinical exclusions. Seventy-eight patients met the entry criteria but refused to comply with the follow-up criteria of yearly visits and undergoing at least one postoperative angiogram. Four hundred thirty-eight patients, 285 in group 1 and 153 in group 2 , were randomly assigned to receive RA grafting or a control graft. In group 1, 140 patients were randomly assigned to RA grafting and 145 to right ITA grafting. In group 2, 73 patients were randomly assigned to RA grafting and 80 were to receive SV grafts. All 438 patients were included for analysis of survival and event-free survival outcomes according to intent to treat.

Angiography enrollment. Thirty-two patients were withdrawn from the graft patency study at the time of surgery because of the poor quality of the randomly assigned conduit (eg, damaged during removal) or extensive calcification. A further 8 patients were withdrawn because the appropriate coronary artery was not grafted and 2 patients withdrew consent, leaving 396 patients who were suitable for a scheduled angiogram during the 10-year study. The decision by the surgeon to alter the operation or grafting strategy, (for example, to operate off-pump in 2 patients, to repair a left ventricular aneurysm, to use a sequential graft, or to perform a proximal anastomosis with the left ITA or the addition of an arterial graft conduit instead of the SV as a subsequent graft) was not considered an indication for removal.

This 5-year interim graft patency study reports the KaplanMeier graft patency estimates of 114 angiograms: 53 protocoldirected angiograms and 61 optional angiograms. The current 
TABLE 3. Major demographic and operative variables

\begin{tabular}{|c|c|c|c|}
\hline & RA (n = 140) & Right ITA (n = 145) & $P$ value \\
\hline \multicolumn{4}{|l|}{ Group 1 (n = 285) } \\
\hline Age $(\mathrm{y}$, mean and $95 \% \mathrm{Cl})$ & $60.1(45.0-75.2)$ & $59.3(44.3-74.3)$ & .35 \\
\hline Gender (No. male) & $120(86 \%)$ & $133(92 \%)$ & .11 \\
\hline Diabetes (No.) & $15(11 \%)$ & $15(10 \%)$ & .77 \\
\hline Hypertension (No.) & $79(59 \%)$ & $67(48 \%)$ & .08 \\
\hline Ejection fraction $<50 \%$ (No.) & $42(30 \%)$ & $29(20 \%)$ & .06 \\
\hline Elective presentation (No.) & $116(83 \%)$ & $127(88 \%)$ & .26 \\
\hline \multirow[t]{2}{*}{ Total grafts (mean and $95 \% \mathrm{Cl}$ ) } & $3.1(1.6-4.6)$ & $3.2(1.5-4.9)$ & .29 \\
\hline & RA (n = 73) & SV $(n=80)$ & \\
\hline \multicolumn{4}{|l|}{ Group 2 (n $=153$ ) } \\
\hline Age $(y$, mean and $95 \% \mathrm{Cl})$ & $72.9(62.3-83.5)$ & $73.2(64.0-82.4)$ & .64 \\
\hline Gender (No. male) & $63(86 \%)$ & $67(84 \%)$ & .66 \\
\hline Diabetes (No.) & $27(37 \%)$ & $37(46 \%)$ & .24 \\
\hline Hypertension (No.) & $39(58 \%)$ & $50(66 \%)$ & .35 \\
\hline Ejection fraction $<50 \%$ (No.) & $22(30 \%)$ & $26(32 \%)$ & .78 \\
\hline Elective presentation (No.) & $68(93 \%)$ & $71(89 \%)$ & .49 \\
\hline Total grafts (mean and $95 \% \mathrm{Cl}$ ) & $3.3(1.4-5.2)$ & $3.2(1.9-4.5)$ & .78 \\
\hline
\end{tabular}

status of the angiography program is summarized in Tables $2 \mathrm{~A}$ and 2B.

\section{Results}

\section{Demographic Characteristics}

There were no significant differences in any of the major demographic and operative variables between experimental and control groups (Table 3).

\section{Graft Patency}

Five-year patency. In group 1, a total of 39 RA grafts were compared with 29 right ITA grafts. One RA graft and no right ITA grafts failed in the 5-year period. RA graft patency estimate was 0.95 (95\% confidence interval [CI] $0.85-0.99)$ versus 1.00 for the right ITA $(P=.4$; Figure 2 , $A)$. In group 2, a total of 24 RA grafts were compared with 22 SV grafts. One SV graft and 3 RA grafts failed. The RA patency estimate was 0.86 (95\% CI 0.67-0.99) versus 0.95 (95\% CI 0.83-0.99) for the SV $(P=.5$; Figure 2, $B)$.

\section{Clinical End Points}

Survival. Eighteen of 438 patients died during the 5 years (Table 4). In group 1, 9 of 285 patients died; survival estimates were 0.96 (95\% CI 0.88-0.99) for the RA subgroup $(\mathrm{n}=140)$ and 0.87 (95\% CI 0.72-0.99) for the right ITA subgroup ( $\mathrm{n}=145, P=.3$ ). In group 2,9 of 153 patients died. The RA subgroup $(\mathrm{n}=73)$ survival was 0.87 (95\% CI 0.67-0.99); the SV subgroup $(\mathrm{n}=80)$ survival was 0.95 (95\% CI 0.83-0.99, $P=.3$ ).

Cardiac event-free survival. In addition to the 18 deaths, there were 8 percutaneous interventions and 3 myocardial infarctions among the 438 patients during the 5-year follow-up (Table 4). In group 1, event-free survival estimates were 0.91 (95\% CI 0.76-0.99) for the RA subgroup (n
$=140)$ and $0.82(95 \%$ CI $0.63-0.99)$ for the right ITA subgroup $(\mathrm{n}=145, P=.7$; Figure $3, A)$. In group 2, event-free survival estimates were 0.84 (95\% CI 0.64-0.99) for the RA subgroup $(\mathrm{n}=73)$ and 0.89 (95\% CI 0.72-0.99) for the SV subgroup $(\mathrm{n}=80, P \leq .9$; Figure 3, B).

\section{Discussion}

This article reports the interim results of a randomized study comparing the patency of the RA used as a coronary artery bypass graft with those of the free right ITA and also the SV during a 5-year period. In the first 5 years after surgery, there were no differences in the angiographic failure rates and major clinical outcomes of the RA compared with the right ITA and with the SV graft. The study indicates that when the RA is harvested carefully and implanted with the use of interoperative and postoperative vasodilators, it is a satisfactory conduit for grafting to a vessel with a good diameter and a high-grade stenosis. This interim report reveals that the patency of the SV and survival of the trial patients are good, compared with previous reports. $8,14,15,26,29,38$

There are a number of reports of RA graft patency in patients who underwent angiography directed by symptoms suggestive of ischemia. ${ }^{14,17,18,22,23,25,39}$ There have been few published results of elective angiograms of the RA when used as a coronary artery bypass graft. The angiographic patency rate from the RAPCO study is similar to other reported RA patency results of studies that were based on ischemic symptoms. Our early SV graft patency appears superior to that recorded previously, suggesting that the choice of a large target artery and factors currently used to protect grafts, such as vasodilators and 3-hydroxy-3methylglutaryl coenzyme A reductase inhibitors, may 

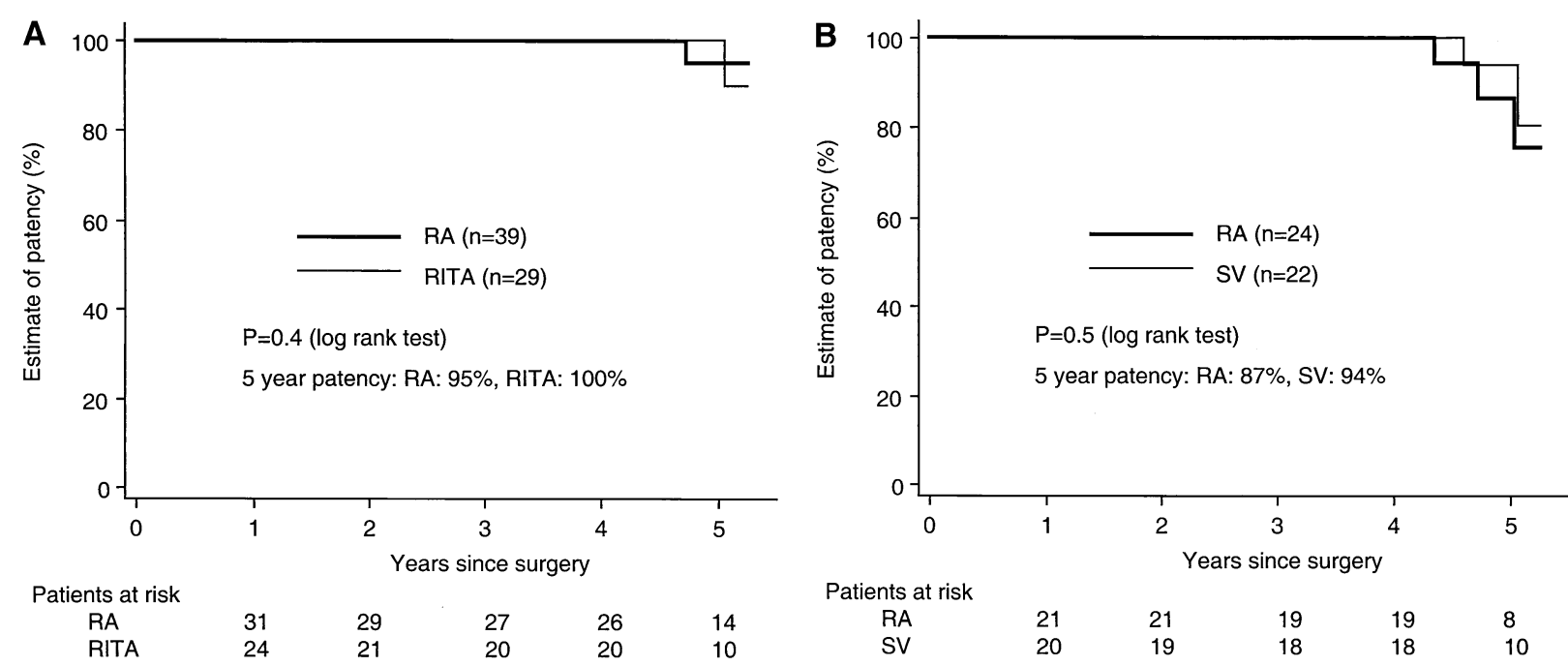

Figure 2. Five year Kaplan-Meier estimates of graft patency. A, Comparison of RA grafts with free right ITA (RITA) grafts. B, Comparison of RA grafts with SV grafts

TABLE 4. Deaths and cardiac events

\begin{tabular}{lcccccc}
\hline & \multicolumn{2}{c}{ Group 1 } & & \multicolumn{2}{c}{ Group 2 } \\
\cline { 2 - 3 } & RA & Right ITA & & RA & SV \\
\hline Deaths $(\mathrm{n}=18)$ & 3 & 6 & 6 & 3 \\
Percutaneous interventions $(\mathrm{n}=8)$ & 3 & 2 & & 1 & 2 \\
Myocardial infarctions $(\mathrm{n}=3)$ & 1 & 1 & & 0 & 1
\end{tabular}

All perioperative and subsequent deaths and cardiac events are included.

have improved the outcomes of both the control and study grafts.

There are two randomized trials that have analyzed graft patency as an end point, one published ${ }^{40}$ and the other in progress. ${ }^{26}$ Fremes $^{26}$ and the RAPS investigators from Sunnybrook (Toronto, Ontario, Canada) have enrolled 560 patients in a prospective multicenter randomized clinical trial comparing the RA patency with that of the SV when grafted to the right or circumflex coronary arteries. This study is comparing the 8- to 12-month protocol-directed angiographic patency of the RA versus the SV coronary bypass grafts, with each patient serving as his or her own control. The primary end point of the study is the proportion of RA and control SV grafts occluded at the time of angiography. TIMI flow and graft stenoses are also recorded. Because the RA and the control SV are used in all patients, however, it will be difficult to attribute a clinical outcome to the use of a particular graft. In contrast, the RAPCO trial has both graft patency and survival end points. The trial was designed with two strata, a younger and older group, which reflects current clinical practice. This study is designed to answer the following questions: Should the surgeon choose an RA or ITA graft in young patients? Should the surgeon favor the RA rather than SV in older patients? There is one trial graft in each patient, compared with two trial grafts in the RAPS. Thus the RAPCO angiographic study is relatively underpowered compared with the RAPS; the power calculation is not time dependent, and therefore it would be expected that if a true difference existed, a longer follow-up period would be required to achieve a statistically significant result. This 5-year interim report represents a small proportion of the expected angiographic results. Compliance with the protocol-directed angiography schedule in the first year was about $80 \%$, although some missed the scheduled date. The clinical end points of survival and freedom from myocardial infarction, percutaneous intervention, and reoperation are robust end points that will continue to be recorded during the next decade.

The categoric angiographic end point of graft failure, defined as occlusion or a stenosis of at least $70 \%$, corresponds with the accepted threshold for intervention in native coronary arteries. Graft failure is defined by occlusion and absence of TIMI 3 flow in the RAPS. ${ }^{26}$ In the RAPCO, trial the string sign was defined as uniform narrowing $(>50 \%)$ of a graft with delayed opacification of the target artery (TIMI 1 or 2 flow) and recorded as graft failure. Similarly, Fremes $^{26}$ defines the string sign as occlusion of the graft. Graft disease may involve the proximal and distal anastomoses. Anastomotic disease may be the result of poor surgical technique, the healing and remodeling process, or disease in the native coronary artery or aorta. Anastomotic disease in the RAPCO trial has been flagged and will be analyzed separately. The angiographic committee will make recommendations on the presurgical entry angiographic criteria and the management of anastomotic disease. Quanti- 

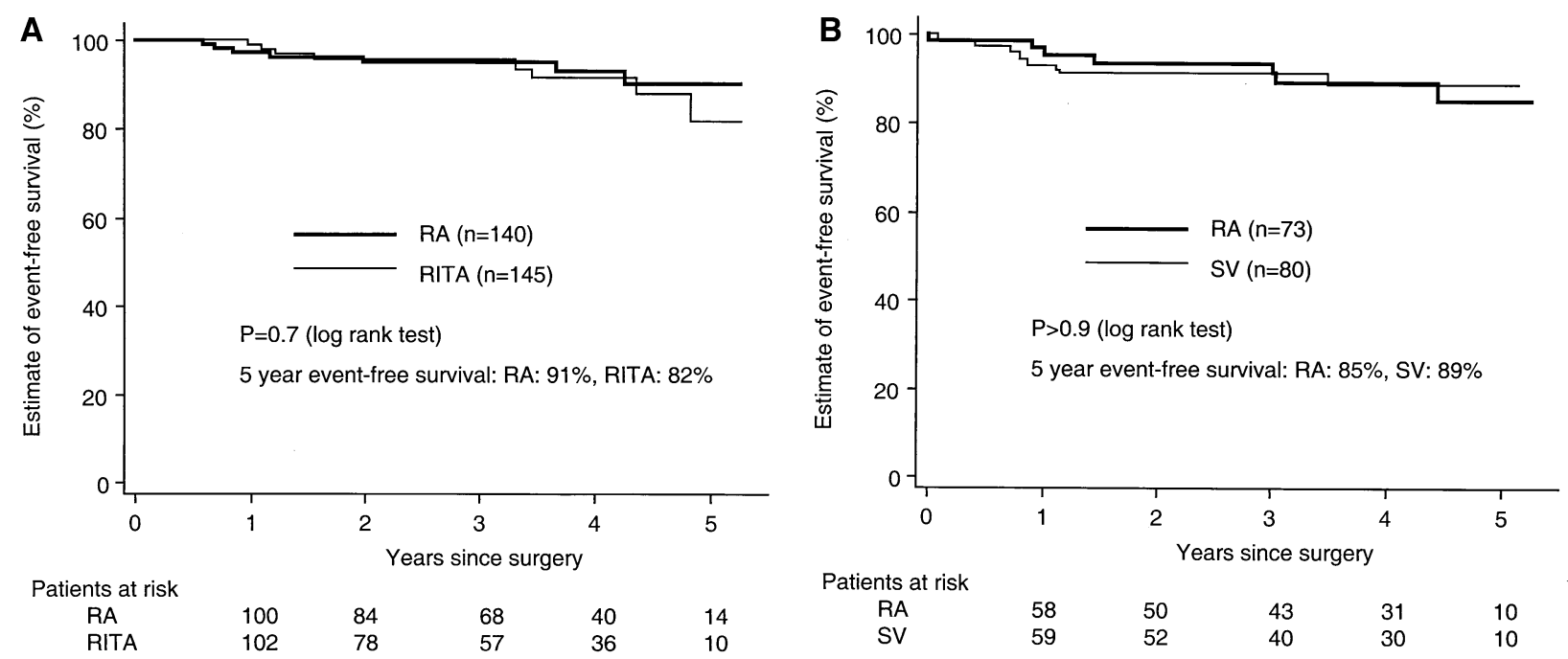

Figure 3. Five-year Kaplan-Meier estimates of cardiac event-free survival. A, Group 1, RA versus free right ITA (RITA). B, Group 2, RA versus SV.

tative coronary angiography will be subsequently undertaken to provide an independent assessment of graft disease.

Protocol-directed angiography, unlike symptom-directed angiography, provides an opportunity to analyze the rate of graft failure in patients both with and without symptoms. There is a paucity of elective angiographic results of conduits in coronary artery surgery. Symptom-directed angiography may select patients with severe disease, thus introducing a bias in the patency rate. Previous data from symptom-directed angiography in our unit suggested that there would be few graft failures in the first 5 years after surgery with SV or ITA grafts; more graft patency end points are expected in the second 5 years. Therefore optional 5-year angiograms, which likewise should not introduce bias, were included in this interim analysis. Furthermore, the 61 optional angiograms provide angiographic data for these elderly patients with associated morbidity, some of whom will die before the protocol-directed angiogram. The choice remains to analyze the protocol-directed angiograms separately from the optional 5-year angiograms. The addition of a second or even a third angiogram to the protocoldirected study has the benefit of allowing assessment of the progression of graft disease.

Time-related analyses of clinical events such as death, reoperation, or myocardial infarction provide an accurate assessment that can be used to predict complication rates and outcomes in a similar population. However, the use of actuarial techniques to assess graft patency is based on the assumption that the event occurs at the time of the angiogram, and absolute failure rates therefore cannot be defined. Graft failure, which may be silent, can occur any time from implantation up to angiography, and rates of failure will therefore be underestimated. Comparisons of relative failure rates of trial versus control grafts are valid, because the same technique and time intervals were used to assess both trial and control grafts.

Improved graft durability would be expected to correlate with fewer clinical events and improved survival. This association is often delayed. Improved survival has been observed with in situ ITAs relative to SV grafts; a decrease in clinical events from the use of a second arterial graft or a different type of arterial conduit is likely to be less dramatic. Those patients who died or were unavailable for follow-up and not identified by the regular clinical follow-up mechanism are readily identified through the Australian National Death Index, ${ }^{36}$ thus providing reliable survival data.

\section{Conclusion}

The 5-year interim results of the RAPCO study do not support the hypotheses that the RA has a superior patency to the free right ITA and the SV when used as a coronary artery bypass graft and that it is associated with fewer clinical events. On the basis of the previous experience of persisting patency of arterial compared with SV grafts, however, the continued evaluation of the RA is justified.

The following participants are acknowledged. Surgeons: George Matalanis, MD, Siven Seevanayagam, MD, Julian Gaer, MD, Anand Dixit, MD, and Masashi Komeda, MD, PhD; cardiologists involved with angiography: Paul Kertes, MD, Keith Woollard, MD, George Proimos, MD, Ron Dick, MD, John Brennan, MD, Anthony Jackson, MD, Robert Chan, MD, Angas Hamer, MD, Les Oliver, MD, Jennifer Johns, MD, Tony Dortimer, MD, Alexander Black, MD, David Clark, MD, Ben Sia, MD, Jack Federman, MD, Allan Appelbe, MD, Julie A. Bradley, MD, and Christopher Webb, MD; intensive care unit physicians: Larry 
McNicol, MD, and Laurie Doolan, MD; editorial staff: Mardi A. Malone; and research nurses: Louise Mullaly, RN, Meg Storer, RN, Cath Cowie, RN, and Catherine Folvig, RN.

\section{References}

1. Berreklouw E, Rademakers PP, Koster JM, van Leur L, van der Wielen BJ, Westers P. Better ischemic event-free survival after two internal thoracic artery grafts: 13 years of follow-up. Ann Thorac Surg. 2001;72:1535-41.

2. Buxton BF, Komeda M, Fuller JA, Gordon I. Bilateral internal thoracic artery grafting may improve outcome of coronary artery surgery. Risk-adjusted survival. Circulation. 1998;98(19 Suppl):II1-6.

3. Lytle BW, Blackstone EH, Loop FD, Houghtaling PL, Arnold JH, Akhrass R, et al. Two internal thoracic artery grafts are better than one. J Thorac Cardiovasc Surg. 1999;117:855-72.

4. Buxton BF, Ruengsakulrach P, Fuller J, Rosalion A, Reid CM, Tatoulis $\mathrm{J}$. The right internal thoracic artery graft-benefits of grafting the left coronary system and native vessels with a high grade stenosis. Eur J Cardiothorac Surg. 2000;18:255-61.

5. Carpentier A, Guermontrez JL, Deloche A, Frechette C, DuBost C. The aorta-to-coronary radial artery bypass graft: a technique avoiding pathological changes in grafts. Ann Thorac Surg. 1973;16:111-21.

6. Acar C, Jebara V, Portoghese M, Beyssen B, Pagny JY, Grare P, et al. Revival of the radial artery for coronary artery bypass grafting. Ann Thorac Surg. 1992;54:652-9.

7. Calafiore AM, Di Giammarco G, Teodori G, D'Annunzio E, Vitolla G, Fino C, et al. Radial artery and inferior epigastric artery in composite grafts: improved midterm angiographic results. Ann Thorac Surg. 1995;60:517-24.

8. Fremes SE, Christakis GT, Del Rizzo DF, Musiani A, Mallidi H, Goldman BS. The technique of radial artery bypass grafting and early clinical results. J Card Surg. 1995;10:537-44.

9. Meharwal ZS, Trehan N. Functional status of the hand after radial artery harvesting: results in 3977 cases. Ann Thorac Surg. 2001;72: 1557-61.

10. Reddy VS, Parikh SM, Drinkwater DC Jr, Lo A, Rauth TP, Moleski RM, et al. Morbidity after procurement of radial arteries in diabetic patients and the elderly undergoing coronary revascularization. Ann Thorac Surg. 2002;73:803-7.

11. Borger MA, Cohen G, Buth KJ, Rao V, Bozinovski J, Liaghati-Nasser $\mathrm{N}$, et al. Multiple arterial grafts. Radial versus right internal thoracic arteries. Circulation. 1998;98(19 Suppl):II7-13.

12. Tatoulis J, Buxton BF, Fuller JA. Bilateral radial artery grafts in coronary reconstruction: technique and early results in 261 patients. Ann Thorac Surg. 1998;66:714-9.

13. Tatoulis J, Royse AG, Buxton BF, Fuller JA, Skillington PD, Goldblatt JG, et al. The radial artery in coronary surgery - a 5 year experience: clinical and angiographic results. Ann Thorac Surg. 2002;73:143-8.

14. Dietl CA, Benoit $\mathrm{CH}$. Radial artery graft for coronary revascularization: technical considerations. Ann Thorac Surg. 1995;60:102-10.

15. Bhan A, Gupta V, Choudhary SK, Sharma R, Singh B, Aggarwal R, et al. Radial artery in CABG: could the early results be comparable to internal mammary artery graft? Ann Thorac Surg. 1999;67:1631-6.

16. Weinschelbaum EE, Gabe ED, Macchia A, Smimmo R, Suarez LD. Total myocardial revascularization with arterial conduits: radial artery combined with internal thoracic arteries. J Thorac Cardiovasc Surg. 1997;114:911-6.

17. Acar C, Ramsheyi A, Pagny JY, Jebara V, Barrier P, Fabiani JN, et al. The radial artery for coronary artery bypass grafting: clinical and angiographic results at five years. J Thorac Cardiovasc Surg. 1998; 116:981-9.

18. Chen AH, Nakao T, Brodman RS, Greenberg M, Charney R, Menegus $\mathrm{M}$, et al. Early postoperative angiographic assessment of radial artery grafts used for coronary artery bypass grafting. $J$ Thorac Cardiovasc Surg. 1996;111:1208-12.

19. Brodman RF, Frame R, Camacho M, Hu E, Chen A, Hollinger I. Routine use of unilateral and bilateral radial arteries for coronary bypass graft surgery. J Am Coll Cardiol. 1996;28:959-63.

20. da Costa FD, da Costa IA, Poffo R, Abuchaim D, Gaspar R, Garcia L, et al. Myocardial revascularization with the radial artery: a clinical and angiographic study. Ann Thorac Surg. 1996;62:475-80.

21. Calafiore AM, Contini M, Vitolla G, Di Mauro M, Mazzei V, Teodori $\mathrm{G}$, et al. Bilateral internal thoracic artery grafting: long-term clinical and angiographic results of in situ versus Y grafts. J Thorac Cardiovasc Surg. 2000;120:990-6.

22. Iaco AL, Teodori G, Di Giammarco G, Di Mauro M, Storto L, Mazzi $\mathrm{V}$, et al. Radial artery for myocardial revascularization: long-term clinical and angiographic results. Ann Thorac Surg. 2001;72:464-9.

23. Royse AG, Royse CF, Tatoulis J, Grigg LE, Shah P, Hunt D, et al. Postoperative radial artery angiography for coronary artery bypass surgery. Eur J Cardiothorac Surg. 2000;17:294-304.

24. Possati G, Gaudino M, Alessandrini F, Luciani N, Glieca F, Trani C, et al. Midterm clinical and angiographic results of radial artery grafts used for myocardial revascularization. J Thorac Cardiovasc Surg. 1998;116:1015-21.

25. Maniar H, Sundt T, Barner H, Prasad S, Peterson L, Absi T, et al. Impact of target stenosis and location on radial artery graft patency. J Thorac Cardiovasc Surg. 2002;123:45-52.

26. Fremes SE. Multicenter radial artery patency study (RAPS). Study design. Control Clin Trials. 2000;21:397-413.

27. Ruengsakulrach P, Brooks M, Hare DL, Gordon I, Buxton BF. Preoperative assessment of hand circulation by means of Doppler ultrasonography and the modified Allen test. J Thorac Cardiovasc Surg. 2001;121:526-31.

28. Kannel WB, McGee DL. Diabetes and cardiovascular disease. The Framingham study. JAMA. 1979;241:2035-8.

29. The Bypass Angioplasty Revascularization Investigation (BARI) Investigators. Comparison of coronary bypass surgery with angioplasty in patients with multivessel disease. $N$ Engl J Med. 1996;335: 217-25.

30. Weintraub WS, Kosinski A, Culler S. Comparison of outcome after coronary angioplasty and coronary surgery for multivessel coronary artery disease in persons with diabetes. Am Heart J. 1999;138:S394-9.

31. Reyes AT, Frame R, Brodman RF. Techniques for harvesting the radial artery as a coronary bypass graft. Ann Thorac Surg. 1995;59: 118-26.

32. Buxton BF, Fuller JA, Gaer J, Liu JJ, Mee J, Sinclair R, et al. The radial artery as a bypass graft. Curr Opin Cardiol. 1996;11:591-8.

33. Tatoulis J, Buxton BF, Fuller JA, Royse AG. The radial artery as a graft for coronary revascularization: techniques and follow-up. $A d v$ Card Surg. 1999;11:99-128.

34. Royse A, Royse C, Shah P, Williams A, Kaushik S, Tatoulis J. Radial artery harvest technique, use and functional outcome. Eur J Cardiothorac Surg. 1999;15:186-93.

35. The TIMI Study Group. The Thrombolysis in Myocardial Infarction (TIMI) trial. Phase I findings. N Engl J Med. 1985;312:932-6.

36. Australian Institute of Health and Welfare. Media release. Heart disease declining but still claims 50,000 lives a year. Available from: http://www.aihw.gov.au/media/2001/mr010430.html.

37. Dobson AJ, Gebski VJ. Sample sizes for two independent proportions using the continuity-corrected arc sine transformation. Statistician. 1986;35:51-3.

38. CASS Principal Investigators and their Associates. Coronary Artery Surgery Study (CASS): a randomized trial of coronary artery bypass surgery. Quality of life in patients randomly assigned to treatment groups. Circulation. 1983;68:951-60.

39. Possati G. Minimally invasive direct coronary artery bypass and the limit between clinical research and practice. Cardiologia. 1999;44: 55-9.

40. Zeff RH, Kongtahworn C, Iannone LA, Gordon DF, Brown TM, Phillips SJ, et al. Internal mammary artery versus saphenous vein graft to the left anterior descending coronary artery: prospective randomized study with 10-year follow-up. Ann Thorac Surg. 1988;45:533-6.

\section{Discussion}

Dr Stephen E. Fremes (Toronto, Ontario, Canada). Buxton and colleagues have contributed greatly to our knowledge of arterial conduits. They have successfully enrolled in this randomized clinical trial a total of 438 patients, all from their own 